\title{
PENGARUH PENGGUNAAN STRATEGI SELF-MANAGEMENT DALAM KONSELING KELOMPOK TERHADAP KECEMASAN BELAJAR SISWA KELAS VIII SMP JALAN JAWA
}

\author{
Rendy Jauhari Hermanto \\ Bimbingan Konseling Universitas PGRI Adi Buana Surabaya \\ jauharirendy@gmail.com \\ Achmad Rifai \\ Bimbingan Konseling Universitas PGRI Adi Buana Surabaya
}

\begin{abstract}
The research method which is used is post experimental with one group pre test post test design. The research sample is 20 students class VIII SMP JALAN JAWA Surabaya which is taken by purposive sampling technique. Data collection technique uses measuring scale which had been done validity test and realiability test alpha cronbach. Validity test of measuring scale study anxiety is between 0,531-0,945, while reliability test alpha cronbach is 0,682. Pretest data and posttest are analyzed by using SPSS for windows version 22 by technique T test statistic parametric after had been done normality assumption test and homogeneities variant. Based on the analysis result, can be concluded that "there is positive influence significantly of using strategy self-management in group counseling to study anxiety of students class VIII SMP JALAN JAWA Surabaya”.
\end{abstract}

Keyword: Self Management, Group Counseling, Anxiety

\section{PENDAHULUAN}

Hartono

(2006:107)

menjelaskan kecemasan adalah suatu kondisi emosi yang dialami oleh seseorang yang merupakan perasaan yang tidak menyenangkan dan merupakan suatu pengalaman yang samar-samar disertai dengan perasaan yang tidak menentu. Pada umumnya kecemasan itu bersifat subjektif, yang ditandai dengan perasaan tegang, takut, khawatir dan terkadang disertai dengan perubahan fisiologis. Misalnya adanya perubahan pernafasan, tekanan darah dan meningkatnya denyut nadi. Siswa yang akan mengalami kecemasan bila menghadapi situasi yang membahayakan dirinya, seperti saat menghadapi ujian, presentasi di depan kelas, diskusi kelompok, dan 
menghadapi ujian UNAS yang dianggap paling sulit.

Berdasarkan hasil survei yang dilakukan oleh Junita (2013:1) diketahui bahwa siswa yang mengalami kecemasan saat belajar adalah $56 \%$ sedangkan $22 \%$ merasa sangat cemas dan $21 \%$ merasa biasabiasa saja. Sebenarnya kecemasan merupakan reaksi normal terhadap situasi yang menekan. Namun dalam beberapa kasus, menjadi berlebihan dan dapat menyebabkan seseorang ketakutan yang tidak rasional terhadap sesuatu hal. Kecemasaan yang cukup lama akan menghilangkan kemampuan untuk merasa bahagia.

Kecemasan itu bisa terjadi kepada siapapun dan dimanapun, termasuk para siswa yang selalu mengalami kecemasaan disaat belajar. Kecemasan yang dialami siswa di sekolah bisa berbentuk kecemasan realistik, neurotik atau kecemasan moral. Kecemasan merupakan proses psikis yang sifatnya tidak tampak ke permukaan maka untuk menentukan apakah seorang siswa mengalami kecemasan atau tidak, diperlukan penelaahan yang seksama, dengan berusaha mengenali simptom atau gejalagejalanya, beserta faktor-faktor yang melatarbelakangi dan mempengaruhinya. Dengan demikian, perlu dicatat bahwa gejalagejala kecemasan yang bisa diamati di permukaan hanyalah sebagian kecil saja dari masalah yang sesungguhnya, ibarat gunung es di lautan, yang apabila diselami lebih dalam mungkin akan ditemukan persoalan-persoalan yang jauh lebih kompleks.

Dampak yang bisa terjadi jika masalah kecemasan siswa tidak segera di atasi adalah adanya pikiran negatif tentang diri sendiri dan lingkungannya, perasaan negatif terhadap kemungkinan kegagalan serta konsekuensi seperti tidak adanya harapan mendapat sesuatu sesuai yang diharapkan, kritis terhadap diri sendiri, menyerah terhadap situasi yang ada, emosi yang tidak stabil, memiliki rasa tidak percaya diri, menimbulkan rasa ketakutan yang tidak rasional terhadap suatu hal dan merasa khawatir berlebihan tentang kemungkinan apa yang dilakukan. 
Faktor-faktor penyebab

timbulnya kecemasan menurut Collin dalam Fahriah (2012:1) mengatakan bahwa kecemasan timbul karena adanya (1) Ancaman, yaitu ancaman yang dimaksud adalah ancaman terhadap tubuh, jiwa atau psikisnya. Misalnya hilangnya konsentrasi saat ulangan, hilangnya konsentrasi saat presentasi dikelas; (2) Pertentangan, yaitu karena adanya keinginan dan keadaan yang bertolak belakang. Misalnya keinginan mendapatkan soal yang mudah saat ulangan namun keadaanya mendapatkan soal yang sulit; (3) Ketakutan yaitu kecemasan yang timbul karena ketakutan akan sesuatu, misalnya ketakutan akan gagal saat menghadapi ujian atau ketakutan saat jam pelajaran tertentu; (4) Kebutuhan yang tidak terpenuhi, yaitu kebutuhan manusia begitu komplek dan apabila kebutuhan tersebut gagal maka timbullah kecemasan.

Hasil penelitian ini diharapkan bermanfaat baik secara teoritis maupun secara aplikatif. Manfaat secara teoritis yang diperoleh adalah untuk memperkaya khasanah ilmu pengetahuan khususnya dalam aspek strategi Self-management dalam konseling kelompok terhadap kecemasaan belajar siswa. Manfaat secara aplikatif yaitu diperolehnya informasi atau data empiris yang bermanfaat untuk pengembangan pelayanan konseling kelompok di SMP JALAN JAWA dan yang sederajat bagi guru bimbingan dan konseling.

\section{METODE}

Penelitian ini menggunakan rancangan praeksperimen yaitu One Group Pretes Postes Design. Sebelum diberikan treatment pada subjek penelitian terlebih dahulu dilakukan pengukuran variabel terikat yaitu kecemasan siswa setelah diberikan treatment berupa penggunaan self-management pada konseling kelompok kemudian dilakukan pengukuran kedua tersebut terhadap variabel kecemasan siswa. Rancangan penelitian ini digambarkan sebagai berikut 


$\begin{array}{ccc}\text { Pre test } & \text { treatment } & \text { Post test } \\ \mathrm{T} 1 & \mathrm{X} & \mathrm{T} 2\end{array}$

Gambar 1. Rancangan penelitian experimental One Group Pretes Postes Design.

Keterangan:

1. T-1 adalah pretes (Pengukuran kecemasan siswa sebelum diberikan treatment)

2. T-2 adalah Postes (Pengukuran kecemasan siswa sesudah diberi treatment)

3. X adalah perlakuan penggunaan strategi self-management.

HASIL

Tabel 1

Statistik Deskriptif Kecemasan Belajar siswa

\begin{tabular}{ccccc}
\hline No & Variabel & N & Mean & Std. Deviation \\
\hline 1 & Kecemasan belajar siswa pree test & 20 & 33.95 & 5.960 \\
& & & & \\
\hline 2 & Kecemasan belajar siwa post test & 20 & 25.95 & 2.982 \\
\hline
\end{tabular}

Tabel di atas, menunjukkan bahwa terjadi peningkatan rerata (Mean) score variabel kecemasan belajar siswa (post-test) setelah diberikan perlakuan strategi selfmanagement. Rata-rata (mean) Score variabel kecemasan belajar siswa (pre-test) sebelum diberikan perlakuan strategi self-management adalah 33,95 sedangkan rata-rata (mean) score variabel kecemasan belajar siswa (post test) setelah diberikan perlakuan strategi selfmanagement menjadi 25,95 terjadi penurunan rata-rata (mean) score variabel kecemasan belajar siswa sebesar 13,9\% dengan demikian penggunaan strategi selfmanagement dalam konseling kelompok dapat mengurangi kecemasan belajar siswa SMP.

PEMBAHASAN

Penelitian pengaruh penggunaan straregi selfmanagement dalam konseling kelompok terhadap kecemasan belajar siswa dengan menggunakan One Group Pre-Test Post-Test Design meghasilkan temuan penelitian yaitu terdapat pengaruh positif yang signifikan penggunaan straregi self-management dalam konseling kelompok terhadap kecemasan belajar siswa. Hal tersebut dapat dicapai karena penelitian melakukan dengan hatihati mulai dari penentuan judul, 
rumusan masalah, mendeskripsikan variabel dan definisi variabel, membuat blue print, membuat item yang kemudian dilakukan uji coba (try out) terlebih dahulu dan hasilnya diuji kadar validitas dan reliabilitas, menguji normalitas sebaran dan linieritas hubungan sebagai syarat statistik parametrik sebelum dilakukan perhitungan dengan teknik uji-t sebagaimana dalam program SPSS for MS Windows versi 16.0.

\section{PENUTUP}

\section{A. Simpulan}

Berdasarkan hasil penelitian yang telah diperoleh, maka dapat disimpulkan bahwa terdapat pengaruh positif yang signifikan penggunaan strategi SelfManagement dalam konseling kelompok terhadap kecemasan belajar siswa kelas VIII SMP JALAN JAWA Surabaya.

\section{B. Saran}

Dengan dibuktikan bahwa terdapat penguruh positif yang dignifikan layanan konseling kelompok terhadap kecemasan belajar siswa kelas VIII SMP JALAN JAWA Surabaya, maka dapat diberikan saran sebagai berikut:

1. Untuk mengurangi kecemasan belajar yang dialami oleh siswa maka perlu diberikan layanan konseling kelompok di sekolah, agar kecemasan yang dialami siswa bisa berkurang dan siswa bisa belajar dengan maksismal.

2. Adakan layanan konseling kelompok setiap bulannya atau persemester agar siswa bisa mengatasi kecemasan yang sering menggangu saat proses belajar mengajar berlangsung.

\section{DAFTAR PUSTAKA}

Aan Setiawan. 2011. Konseling Kelompok (Online), (Http://kajarmimpi.

Blogspot.com diakses tanggal 23 Januari 2015 pukul 12.00 WIB.)

Andri Andika. 2011. Definisi Konseling Kelompok, (Online), (www.Rianddiha. Blogspot.com diakses tanggal 28 Januari 2015 pukul 14.00). 
Ardial Maqasary. 2012. Pengertian dan Ciri-ciri Kecemasan, (Online),

(www.psychologymania.net diakses tanggal 30 Januari 2015 pukul 15.00 WIB).

Dwi Atmaja. 2012. Kegunaan Hasil Penelitian, (Online), (www.wayanwordpres. com, diakses tanggal; 11 April 2015 pukul 17.15 WIB ).

Eka Pramana Putra. 2013. Tersedia pada

http://ejournal.undiksha.ac.id, diakses pada tanggal 25 Januari 2015 pukul 13.00 WIB.

Fahriah Safarini. 2012. Fakotr Penyebab Kecemasan, (Online), (www.elfahri. Blogsop.com, diakses tanggal 11 Juli 2014 pukul 18.38 WIB).

Freed burner. 2012. Ciri-ciri Kecemasan, (Online), (www.freedburner.blogspot. com, dikases pada tanggal 12 September 2013).

Haryanto.2010. Pengertian Belajar, (Online),

(www.belajarpsikologi.com diakses pada tanggal 30 Januari 2015 pukul 13.00 WIB).

Hartono. 2006. Pendekatan Kelompok dalam Konseling Karier. Surabaya: universitas press UNIPA Surabaya
Hartono dan Boy Soedarmadji. 2006. Psikologi Konseling. Surabaya: universitas press UNIPA Surabaya.

Joe galon. 2009.Pengertian belajar,(Online), (http://joegolan. wordpress.com, diakses tanggal 29 september 2013 pukul 10.14 WIB).

Laode Minir. 2013. Pengertian Konseling Kelompok, (Online), (http://laodemunir.blogspot.c om, diakses tanggal 12 februari 2015 pukul 20.46 WIB).

Lutfi Fauzan. 2009. Kajian Psikologi,(Online), (http://kajianpsikologi.blogsp ot.com, diakses tanggal 14 februari 2015 pukul 19.50 WIB).

M. Nur Ghofron. 2010. Teori-teori Psikologi. Jogjakarta: ar-ruzz media.

M. Faizal. 2013. Pengertian Belajar, (Online), (Http://faizalwordpress.com diakses tanggal 20 Januari 2014 WIB).

Muchilisin Riadi. 2013. Pengertian Konseling Kelompok, (Online), (www.kajian, pustaka.com, diakses tanggal 29 Januari 2015 pukul 13.00 WIB).

Nancy Junita. 2012. Tersedia pada www.kabar24.com, diakses tanggal 25 januari 2014 pukul 14.00 WIB. 
Rindu. 2012.Pengertian dan Faktor Kecemasan, (Online), (www.duniapsikologi. com, diakses tanggal 28 Januari 2015 pukul 19.00 WIB)

Saifuddin Azwar. 2007. Penyusunan Skala Psikologi. Yogyakarta: Pustaka Pelajar.
SaifuddinAzwar. 2010. Reliabelitas dan Validitas. Yogyakarta: Pustaka Pelajar

Sumadi Suryabrata. 2003. Metodologi Penelitian. Jakarta: PT Raja Grafindo. 
